\title{
PART ICIPAÇÃO DA MULHER NO PROCESSO DECISÓRIO NO CICLO GRAVÍDICO-PUERPERAL: revisão integrativa do cuidado de enfermagem
}

\author{
Josefine BU SANELLOa, W ilson Danilo LUNARDI FILHOb, \\ Nalú Pereira da Costa KER RE Rc, Valéria Lerch LUNARDIc, Silvana Sidnei dos SANT OSc
}

\section{RESUM 0}

T rata-se de uma revisão integ rativa que objetivou identificar a contribuição do cuidado de enfer magem, descrito nas publicações científicas nacionais, para a participação da mulher no processo decisório no ciclo gravídicopuerperal. As produções científicas foram buscadas em maio de 2010, nas bases de dados da Biblioteca Virtual em Saúde. D os oito artigos que compuser am a revisão, despontaram dois núcleos temáticos: Contribuiç̧ões do cuidado de enfermagem à participação da mulher no processo decisório no ciclo gravídico-puerperal; e Limitações do cuidado de enfermagem à participação da mulher no processo decisório no ciclo gravídico-puerperal. A presente revisão traz subsídios para a produção do conhecimento da Enfermagem, ao identificar uma lacuna na área do conhecimento eatuação dos enfermeiros, evidenciada pela inexistência de pesquisas da E nfer mag em que abordem, especificamente, a participação da mulher no processo decisório no ciclo gravídico-puerperal, e as possíveis contribuições do cuidado de enfer magem para a garantia desse direito.

D escritores: Cuidados de enfermagem. Saúde da mulher. D ireitos da mulher.

\section{RESUMEN}

Se trata de una revisión integradora, con el objetivo de identificar la contribución de los cuidados de enfermería, que se describe en las publicaciones científicas, a cerca de la partici pación de las mujeres en la toma de decisiones en el ciclo grávido puer peral. Se han buscado los estudios científicos en las bases de datos de la Biblioteca Virtual en Salud, en mayo de 2010. D e los ocho estudios que han surgido al examen, emergieron dos temas: las contribuciones de los cuidados de enfermería a la participación de las mujeres en la toma de decisiones en el embarazo, par to y puer perio; $L$ as limitaciones de los cuidados de enfermería a la partici pación delas mujeres en la toma dedecisiones en el embarazo, parto y puerperio. E sta revisión proporciona subvenciones para la producción de conocimiento de enfermería mediantela identificación de una brecha en el conocimiento y el desempeño de las enfermeras, como lo demuestra la falta de investigación en enfermería que aborde específicamente la participación de las mujeres en la toma dedecisiones en el embarazo y el puer perio, y las posi bles contribuciones del os cuidados de enfermería para garantizar ese derecho.

Descriptores: A tención de enfermería. Salud de la mujer. D erechos de la mujer.

T ítulo: L a participación delas mujeres en la toma dedecisiones en el embarazo, parto y puer perio: una revisión integradora dela atención de enfermería.

\section{ABST RACT}

This is an integrative review that aims to identify the contribution of nursing care for woman's participation in the decision process of the pregnancy and puer peral cycle, as described in B razilian scientific publications. The scientific productions w ere retrieved in M ay, 2010, from the Virtual L ibrary of $\mathrm{H}$ ealth (B iblioteca Virtual em Saúde) database F rom the eight articles review ed, two themes stood out: Contributions of nursing care to the woman's participation in the decision process of the pregnancy and puer peral cycle; and L imitations of nursing care to the woman's participation in the decision process of the pregnancy and puer peral cycle T he following review supports the production of knowledge in nursing, by identifying a gap in what nurses know and do about this issue, as show $n$ by thelack of nursing researches that concern, specificall y, the participation of thew oman in the decision process during the pregnancy and puer peral cycleand the possible contributions of nursing care to ensure women of this right.

D escriptors: N ursing care. Women's health. Women's rights.

Title: Woman's participation in the decision process of the pregnancy and puer peral cycle: nursing care integrative review.

a M estre em Enfermagem, Doutoranda do Programa de Pós-Graduação em Enfermagem da Escola de Enfermagem da Universidade Federal do Rio Grande (F URG), Professora Assistente do Curso de Enfermagem da U niversidade Federal do Pampa, U ruguaiana, Rio Grande do Sul, Brasil.

b D outor em Enfermagem, Professor do Programa de Pós-Graduação em Enfermagem da Escola de Enfermagem da FU RG, Rio G rande, Rio Grande do Sul, Brasil.

' D outora em Enfer magem, Professora do Programa de Pós-G raduação em Enfer magem da E scola de Enfermagem da FU RG, Rio G rande, Rio G rande do Sul, Brasil. 


\section{INT RODUÇÃO}

O cuidado ao ciclo gravídico-puerperal compreende o conjunto de serviços destinados ao atendimento da gestante, parturiente, puérpera e recémnascido. Nesse contexto, a qualidade da atenção em saúde envolve atitudes e comportamentos que contribuam para reforçar o caráter de atenção em saúde como um direito, e o grau de informação das muIheres em relação ao seu corpo e suas condições de saúde, ampliando sua capacidade de fazer escolhas adequadas ao seu contexto e momento de vida(1).

Todavia, estudos que abordam a atenção à saúde da mulher durante o ciclo gravídico-puerperal, revelam que a capacidade das mulheres para definirem, analisarem e atuarem sobre o seu próprio corpo vem sendo violada ${ }^{(2-4)}$. A pesar da relevância do tema, constata-se que são raras as discussões e produções cientificas da Enfermagem, relacionadas a essa problemática, no âmbito nacional.

Diferentemente, no contexto internacional, é crescente o número de produções científicas da E nfermagem, acerca dessa temática. D e acordo com um estudo bibliográfico, que teve como fonte a base de dados Cumulative Index to $\mathrm{N}$ ursing and Allied $\mathrm{H}$ ealth $\mathrm{L}$ iterature (CINAHL), no âmbito internacional, a participação da mulher nas decisões nos cuidados que envolvem sua saúde, se constitui um área temática abordada pela $\mathrm{E}$ nfermagem com destaque na perspectiva do ensino, pesquisa e assistência ${ }^{(5)}$.

A construção do conhecimento da Enfermagem nessa área é significativa, visto que no contexto dos cuidados no ciclo gravídico-puerperal, historicamente, as decisões acerca da saúde da muIher estiveram fundamentadas nos sistemas paternalistas da assistência à saúde, nos quais os prestadores do cuidado decidem pelos pacientes. Somado a isso, presencia-se o direcionamento emergente das ações em saúde para um novo paradigma do cuidado, voltado para o modelo humanístico.

N esse modelo de atenção humanizada, a muIher é considerada o sujeito de todas as ações relacionadas à sua saúde, sendo isto possível, por meio do compartilhamento das decisões entre a mulher e os profissionais da saúde, destacando-se o enfermeiro. Assim, entende-se que o enfermeiro possui um papel importante no resgate do direito das mulheres de participar das decisões e problemáticas que podem advir durante o ciclo gravídico- puerperal. Por outro lado, quando as práticas de cuidado à mulher são fundamentadas no autoritarismo e alienação, o enfermeiro poderá contribuir para manter a mulher em uma posição de submissão e aceitação, restringindo sua participação no processo decisório.

$\mathrm{N}$ esta perspectiva, este estudo apresenta a seguinte questão norteadora: Qual a contribuição do cuidado de Enfermagem na participação da muIher no processo decisório no ciclo gravídico-puerperal? Buscando respostas a esse questionamento, tem-se como objetivo: identificar a contribuição do cuidado de enfermagem, descrito nas publicações científicas nacionais, na participação da mulher no processo decisório no ciclo gravídico-puerperal.

\section{MET ODOLOGIA}

T rata-se de uma revisão integrativa, método que tem como finalidade sintetizar as pesquisas publicadas, para obter novas conclusões a partir de um tema de inter esse. $\mathrm{N}$ a oper acional ização dessa revisão, utilizaram-se as seguintes etapas: delimitação do objetivo; definição dos critérios de inclusão das produções científicas; busca dos estudos nas bases de dados; análise dos resumos dos estudos; seleção dos estudos, de acordo com os critérios de inclusão; avaliação criteriosa e fichamento dos estudos selecionados; e anál ise dos dados ${ }^{(6,7)}$.

A pós a definição do objetivo do estudo, prosseguiu-se com a etapa de levantamento bibliográfico, em todas as bases de dados da Biblioteca Virtual em Saúde, no mês de maio de 2010, sem delimitação do período de publicação e utilizando as seguintes combinações de descritores: saúde da muIher e cuidados de enfermagem; gestação e cuidados de enfermagem; parto e cuidados de enfermagem; puer pério e cuidados de enfer magem.

F oram encontradas 438 publicações. A partir da leitura exploratória dos resumos desses materiais bibliográficos encontrados, foram selecionadas 19 publicações, de acordo com os seguintes critérios de inclusão: enfocar a saúde da mulher no Brasil; estar em idioma português, inglês ou espanhol; e despontar como o cuidado de E nfermagem contribui para a participação da mulher no processo decisório no ciclo gravídico-puerperal.

A pós 0 acesso ao texto completo desses 19 estudos, os mesmos foram lidos na íntegra. Ainda nessa fase de seleção, foram excluídos 11 estudos que não contemplaram o último critério de inclu- 
são, revelando uma incoerência entre os resultados apresentados no estudo concluído e no seu resumo.

Assim, após esse procedimento, oito produções científicas foram selecionadas para compor a presente revisão integrativa, sendo estas identificadas com números sequênciais de um a oito. Posteriormente, esses artigos passaram por uma avaliação criteriosa, de modo a compor um fichamento baseado no instrumento de coleta de dados que conteve as seguintes questões: identificação numérica do artigo; citação do artigo; obj etivo(s); referencial teórico; e aspectos relativos à contribuição do cuidado de E nfer magem para a participação da muIher no processo decisório no ciclo gravídico-puerperal.

Salienta-se que os procedimentos de coleta, seleção dos artigos, e de fichamento dos dados, fo- ram realizados por dois autores e, posteriormente, os dados for am comparados, buscando verificar a regularidade.

Foi utilizada a análise qualitativa, desenvolvida por meio da leitura analítica(8), seguindo as etapas de: análise textual, realizada a partir da leitura cuidadosa dos artigos, obtendo-se uma visão mais abrangente dos dados; anál ise temática, buscando esclarecimentos a respeito do tema abordado; e análise interpretativa, na qual se desenrolou a problematização dos achados.

\section{RESULTADOS}

Os achados foram dispostos em dois quadros. 0 Quadro 1 apresenta a citação, o objetivo(s) e o referencial teórico dos artigos analisados, que são descritos e discutidos na sequência do texto.

\begin{tabular}{|c|c|c|c|}
\hline Artigo & Autores/ Ano & Objetivo(s) & Referencial \\
\hline 1 & $\begin{array}{l}\text { Queiroz, Silva, Jorge, } \\
2003\end{array}$ & $\begin{array}{l}\text { Descrever as atividades da equipe de Enfer magem na } \\
\text { assistência à mulher em unidade de inter nação obsté- } \\
\text { trica; Compreender os aspectos da assistência à puérpera } \\
\text { que contribuem para um cuidado humanizado. }\end{array}$ & $\begin{array}{l}\text { Política de } \\
\text { Humanização }\end{array}$ \\
\hline 2 & $\begin{array}{l}\text { Figueirêdo,T yrrell, } \\
\text { Carvalho, Leite, } 2004\end{array}$ & $\begin{array}{l}\text { I dentificar e discutir as ações de Enfermagem quando } \\
\text { cuidam de mulheres durante o pré, trans e pós-parto. }\end{array}$ & N ão especificado \\
\hline 3 & $\begin{array}{l}\text { Castro, Clapis, } \\
2005\end{array}$ & $\begin{array}{l}\text { I dentificar a percepção das enfermeiras obstetras sobre } \\
\text { humanização da assistência ao parto. }\end{array}$ & $\begin{array}{l}\text { Política de } \\
\text { Humanização }\end{array}$ \\
\hline 4 & $\begin{array}{l}\text { Quitete, Vargens, } \\
2009\end{array}$ & $\begin{array}{l}\text { A presentar como mulheres enfermeiras cuidam de mu- } \\
\text { Iheres usuárias, considerando o cuidado como instru- } \\
\text { mento de empoderamento. }\end{array}$ & N ão especificado \\
\hline 5 & $\begin{array}{l}\text { Progianti, Costa, } \\
2008\end{array}$ & $\begin{array}{l}\text { Realizar uma reflexão sobre o cuidado implementado } \\
\text { na Casa de Parto sob a ótica da enfermagem transcul- } \\
\text { tural; ; presentar a educação em saúde como instrumen- } \\
\text { to de negociação das abordagens humanizadas nas prá- } \\
\text { ticas assistenciais. }\end{array}$ & $\begin{array}{l}\text { Teoria do Cuidado } \\
\text { Cultural de L eininger }\end{array}$ \\
\hline 6 & $\begin{array}{l}\text { Iserhard, N eves, } \\
\text { Budó, Badke, } \\
2009\end{array}$ & $\begin{array}{l}\text { Compreender a influência do contexto cultural no de- } \\
\text { senvolvimento da gestação e no cuidado ao bebê de } \\
\text { mulheres mães de recém-nascidos de risco. }\end{array}$ & $\begin{array}{l}\text { Política de } \\
\text { Humanização }\end{array}$ \\
\hline 7 & $\begin{array}{l}\text { Souza, Cubas, } \\
\text { Arruda, Carval ho, } \\
\text { Carvalho, } 2008\end{array}$ & I dentificar as necessidades sociais em saúde da puér pera. & $\begin{array}{l}\text { Teoria de Inter venção } \\
\text { Prática de E nfermagem } \\
\text { em Saúde Col etiva }\end{array}$ \\
\hline 8 & $\begin{array}{l}\text { Carraro et al., } \\
2006\end{array}$ & $\begin{array}{l}\text { Conhecer a opinião de mulheres puérperas sobre os } \\
\text { métodos utilizados para seu cuidado e conforto durante } \\
\text { seu trabal ho de parto e parto. }\end{array}$ & N ão especificado \\
\hline
\end{tabular}

Q uadro 1 - Distribuição dos artigos de acordo com a citação, objetivo e referencial teórico adotado. 
No Quadro 1, observa-se que, na perspectiva do cuidado de Enfermagem, a participação da mulher no processo decisório no ciclo gravídicopuerperal, foi retratada nas produções cientificas da Enfermagem, a partir de 2003. Esse marco pode ser considerado tardio, pois, a implementação das políticas públicas de saúde voltadas para essa população, ocorreu desde 1983 e evocam a garantia do envolvimento da mulher nas decisões sobre sua saúde ${ }^{(1)}$.

A partir do objetivo(s) dos artigos, evidenciase que não foram encontrados estudos com a finalidade de verificar e avaliar, especificamente, a contribuição do cuidado de Enfermagem sobre a participação da mulher no processo decisório no ciclo gravídico-puerperal. No entanto, a abordagem desse direito da mulher despontou na maioria das produções científicas analisadas, que buscaram analisar as ações, as atividades e a assistência desenvolvidas no cuidado de E nfermagem. Esse achado representa que o enfoque da participação das mulheres nas decisões acerca da sua saúde e processo reprodutivo, emerge no contexto de atenção à saúde da mulher.

Ainda em relação ao objetivo, verifica-se que a parturição e puerpério foram os principais momentos do período gravídico-puerperal, enfocados pelos artigos. 0 cuidado de Enfermagem no pré-natal é abordado em um estudo. Esse achado pode ser caracterizado como uma lacuna do conhecimento e de atuação da Enfermagem. A gestação também se constitui em um período importante para garantir a saúde e evitar possíveis complicações maternas e fetais, no qual deveriam ser enfatizadas as práticas educativas, voltadas à ampliação do conhecimento da mulher sobre seu corpo, sua condição de saúde, e seus direitos como cidadã (1)

Evidencia-se, no Quadro 1, que o principal referencial teórico que sustenta os artigos analisados foi a Política de Humanização. Essa preferência pode estar atrelada ao fato de que esse ideário de atenção à saúde fundamenta as principais políticas públicas de saúde voltadas para a mulher, no âmbito nacional. Na perspectiva do ciclo gravídicopuerperal, a proposta de humanização também congrega ações que visam a autonomia e o envolvimento dos sujeitos nas decisões, além da não violência de gênero(1). Por isso, mesmo que o enfoque principal dos artigos anal isados tenha sido a participação da mulher no processo decisório, essa te- mática emergiu nos resultados dos estudos, considerando que os direitos das mulheres são os aspectos mais evocados na proposta de humanização.

0 Q uadro 2 retrata a relação entre as produções científicas que compuseram a presente revisão e os seguintes núcleos temáticos que emergiram da sua análise: Contribuições do cuidado de enfermagem à participação da mulher no processo decisório no ciclo gravídico-puerperal, e L imitações do cuidado de enfermagem à participação da mulher no processo decisório no ciclo gravídicopuerperal. $\mathrm{N}$ a sequência do texto, esses núcleos temáticos são detal hados e discutidos.

\begin{tabular}{|c|c|c|}
\hline Artigos & $\begin{array}{c}\text { Síntese das } \\
\text { contribuições }\end{array}$ & $\begin{array}{c}\text { Síntese das } \\
\text { limitações }\end{array}$ \\
\hline 1 & Temática presente & T emática presente \\
\hline 2 & Temática ausente & T emática presente \\
\hline 3 & Temática presente & T emática presente \\
\hline 4 & Temática presente & Temática presente \\
\hline 5 & Temática presente & T emática ausente \\
\hline 6 & Temática presente & T emática presente \\
\hline 7 & Temática presente & T emática presente \\
\hline 8 & Temática ausente & T emática presente \\
\hline
\end{tabular}

Q uadro 2 - Distribuição dos artigos de acordo com as contribuições e limitações do cuidado de Enfermagem à participação da muIher no processo decisório no ciclo gravídico-puerperal.

\section{Contribuições do cuidado de enfermagem à participação da mulher no processo decisório no ciclo gravídico-puerperal}

Nos artigos analisados, foi possível verificar que o cuidado de E nfer magem pode contribuir para a participação da mulher na tomada decisões acerca da sua saúde, ao valorizar e implementar práticas educativas no campo da atenção obstétrica(9-11). 0 processo educativo necessita ter como finalidade o estimulo à reflexão e à ação positiva das muIheres, acerca do seu corpo e do seu processo reprodutivo ${ }^{(9)}$. Para tanto, é imprescindível que o E nfermeiro respeite a individualidade e a sensibilidade feminina, considerando que o período gravídicopuerperal, acomete importantes transformações físicas e emocionais na mulher ${ }^{(10)}$. 
N esse contexto educativo, é destacada a importância do compartilhamento de práticas e saberes, a partir de uma relação horizontal entre a mulher e o Enfermeiro(10). A ssim, a educação em saúde passa a se constituir como uma estratégia potencializadora do cuidado de E nfer magem no ciclo gravídico-puerperal, sendo capaz de promover a adoção de medidas importantes e benéficas para a saúde materna e do bebê, com a participação da mulher(10,11).

Para reforçar o protagonismo da mulher durante o ciclo gravídico-puerperal, verifica-se que as práticas educativas desenvolvidas pelo E nfermeiro precisam envolver todos os sujeitos que estão próximos à mulher durante esse período $0^{(9,10)}$. As discussões e orientações promovidas acerca do ciclo gravídico-puerperal à mulher precisam ser estendidas aos familiares, tendo em vista a influencia dessas pessoas no cuidado e nas decisões da muIher ${ }^{(10)}$. I sto inclui, também, a sensibilização da equipe de Enfermagem para essa questão, sendo que esses trabal hadores, ao realizarem o cuidado na gestação, parto e puerpério, necessitam respeitar os direitos das mulheres ${ }^{(9,12)}$

Para desenvolver práticas educativas no âmbito da saúde, o Enfermeiro precisa considerar a manifestação das crenças, da inter ação e das ideias da população, compreendendo que os limites da liberdade são estabelecidos na relação com o outro como sujeito. N esta perspectiva, a educação favorece que todos os envolvidos reconheçam sua condição de sujeito e sua responsabilidade pela própria saúde ${ }^{(13)}$.

Ao ampliar o conhecimento das mulheres sobre sua saúde e seus direitos, o Enfermeiro pode favorecer a autonomia e, assim, garantir a sua participação na tomada de decisões no ciclo gravídicopuerperal ${ }^{(11)}$. 0 envolvimento da mulher no contex to do cuidado, pode ser estimulado pelo E nfermeiro, como por exemplo, na auto introdução do espéculo no momento do exame obstétrico. Essa estratégia empregada no cuidado de E nfermagem, além de favorecer o conhecimento e apropriação da mulher sobre seu próprio corpo, reconhecimento da condição de como sujeito ativo no planejamento dos cuidados e na prevenção de agravos da sua saúde ${ }^{(10)}$.

Essas estratégias, adotadas pelos profissionais da E nfermagem, podem contribuir para 0 envolvimento da mulher nas decisões pertinentes ao contexto do cuidado, durante o ciclo gravídico puerperal. No entanto, é imprescindível o entendimento de que a promoção da participação da muIher na tomada de decisões sobre seu próprio cuidado não está relacionada à transferência das funções e responsabilidades, dos profissionais de Enfermagem, para as mulher es ${ }^{(13)}$.

No contexto do cuidado de Enfermagem, reconhecer o paciente como um ser com capacidade para pensar e participar das decisões frente às diferentes alter nativas de cuidado, significa respeitar sua posição de sujeito. Além disso, ao considerar o paciente como agente das mudanças e sujeito da sua condição de saúde, é importante e necessário que os profissionais da Enfermagem considerem a individualidade de cada paciente e valorize o seu contexto de vida ${ }^{(13)}$.

0 cuidado de Enfermagem pode possibilitar e/ ou facilitar a capacidade da mulher desenvolver ou simplesmente fazer escol has sobre seu corpo e seu processo reprodutivo. Diante disso, o cuidado deE nfer magem pode assumir uma perspectiva ainda mais positiva em relação à gar antia dos direitos da mulher, pois quanto maior o envolvimento das mulheres nas decisões, maior sua capacidade do exercício da autonomia ${ }^{(14)}$.

N esta perspectiva, é imprescindível que o enfermeiro reconheça o contexto social e cultural da mulher. As alternativas do cuidado popular estão emersas nas crenças e costumes do meio no qual está inserida a mulher e a sua família. 0 conhecimento dessa realidade pode auxiliar o enfer meiro a compreender como a mulher vivencia e se adapta ao ciclo gravídico-puerperal, e assim, favorecer a participação da mulher no processo decisório(15).

Para tanto, as tecnologias leves são apontadas como instrumentos do processo de trabalho do enfermeiro que devem estar presentes no cuidado à mulher no ciclo gravídico-puerperal(10,11). 0 diálogo é uma tecnologia importante nesse processo ${ }^{(10)}$, a partir do qual há o favorecimento da construção de relações em que os sujeitos, mulher e os profissionais da E nfermagem, em situações reais, do contexto de vida e saúde, tenham condições de identificar as necessidades e alternativas para alcançar o bem-estar na gestação, parto e puer pério(11).

0 modelo de humanização da atenção ao ciclo gravídico puerperal, desde de sua implementação, em 2000, pelo Programa de Humanização do Pré-N atal e Parto, proporcionou um novo paradigma na assistência à mulher. A proposta de humanizar as ações direcionadas à mulher, esta sen- 
do incorporada nos cuidados de Enfermagem. A humanização sustenta princípios como a qualidade da assistência e o respeito aos direitos da muIher, este último, considerado um importante aspecto que garante a participação das mulher es nas tomada de decisões durante o ciclo gravídicopuerperal ${ }^{(9,10,16)}$.

A humanização da atenção ao ciclo g ravídicopuerperal, também requer o resgate dos cuidados naturais, ou seja, o respeito à fisiologia que envolve esse período. As manifestações instintivas da muIher, durante a gestação, parto e puerpério, precisam ser preservadas, com o mínimo possível de práticas inter vencionistas. Este cuidado de E nfermagem tem como principal finalidade favorecer que a mulher e a equipe de saúde tenham a compreensão acerca das fases da mater nidade, como um processo natural, e que a própria mul her se perceba como protagonista desse processo ${ }^{(10,16)}$.

\section{Limitações do cuidado de enfermagem à participação da mulher no processo decisório no ciclo gravídico-puerperal}

Os estudos apontam que o cuidado de E nfermagem pode desfavorecer a participação da muIher no processo decisório, no momento em que o ato comunicativo das mulheres é bloqueado pela autoridade dos trabalhadores da Enfermagem e pela supremacia dos seus conhecimentos científi$\cos ^{(9,15,16)}$. Esses aspectos são agravados pela desconsider ação dos trabalhadores da E nfermagem, do conhecimento popular, prevalecendo o saber empírico em detrimento da valorização da experiência e vivência das mulheres ${ }^{(15)}$.

A postura dos profissionais da E nfermagem, ao dispensar o espaço para a palavra, enfatiza o silêncio e a ausência do diálogo. A ssim, passa a considerar que o saber está sob o domínio de quem cuida, negando e desconhecendo a capacidade do outro, o ser cuidado, como uma pessoa capaz de pensar, divergir e decidir ${ }^{(13)}$.

A invasão e a violência ao corpo da mulher são apontadas como atos que revelam as atitudes autoritárias dos trabalhadores de Enfermagem, principalmente no pré-parto, parto e puerpério imediato. A falta de respeito à privacidade da muIher, em relação ao seu corpo e sua intimidade, e a sua despersonal ização, ou seja, a per da da sua identidade e singularidade são apontadas como atitudes que, ao serem incorporadas nas coes do cuida- do de Enfermagem, fazem com que as mulheres não se sintam sujeitos desse processo ${ }^{(12,17)}$.

$\mathrm{Na}$ Enfermagem, como nas demais relações socais, as relações de poder também são eminentes, no entanto, mais no estado de dominação, visto que há falta de liberdade de escolhas. A relação estabel ecida entre quem pratica a Enfermagem e quem recebe sua atenção, parece ser uma relação, predominantemente desigual entre os sujeitos. 0 reconhecimento do outro, como um ser autônomo, pode ficar comprometido no momento em que alguém assume responsabilidade pela saúde do outro, sem considerar a participação desse outro no desenvolvimento do cuidado ${ }^{(13)}$.

Essa relação de dominação está fortemente associada à posição de submissão e aceitação das mulheres, resultado da intensa manifestação de sentimentos que podem acompanhar o período gravídico-puerperal, tais como a dependência aos cuidados de Enfermagem, a dor e o medo ${ }^{(12,17)}$. A mulher se expõe à vontade da equipe de enfermagem, sendo, muitas vezes, tratada como um ser assexuado, apesar de estar no pleno exercício de sua sexualidade ${ }^{(12)}$

N essa relação de obediência e de aceitação, por parte do ser cuidado em relação à Enfermagem, os profissionais desta área agem como se reconhecessem e se percebessem responsáveis pelo outro, que se torna o objeto do cuidado. Assim, ao decidir pelo paciente o que é melhor para ele, antecipando-se, possivel mente de modo desnecessário, às suas manifestações e à suas necessidades, os profissionais da E nfermagem podem retirar destes a sua condição de ser sujeito da sua própria saúde e de decisão pessoal ${ }^{(13)}$.

A presenta-se uma reflexão importante que releva essa relação conflitante na cena do parto: "O corpo traído, também é o corpo contido, amarrado à mesa de parto pelas per nas [ ...] todos a sua volta, estão com pressa, e por isso, se movimentam em tor no dele, com coisas e expressões que el e não entende. É um corpo totalmente controlado, tanto no seu aspecto exterior, quanto na sua estrutura interior"(17).

A lém da postura dominadora dos trabal hadores da E nfermagem, as próprias mulheres não reconhecem a importância da sua participação no processo decisório, acerca do seu corpo, do seu processo reprodutivo e dos direitos como cidadã ${ }^{(12,14)}$ As mulheres consideram a autonomia como a necessidade menos importante, durante o puerpério. 
Esse dado pode ser o resultado da reprodução das iniquidades sociais, econômicas e de gênero, as quais as mulheres, muitas vezes, estão submetidas ${ }^{(11)}$.

As mulheres, ao buscarem os cuidados de saúde no ciclo gravídico-puerperal, se entregam ao sistema de saúde, em especial, nos casos dos serviços públicos ${ }^{(12)}$. Entre as mulheres e, por vezes, também entre os trabalhadores de Enfer magem, não há o entendimento de que, mesmo sendo público e gratuito, o cuidado de qualidade, seguro e respeitoso, é um direito de todos os cidadãos.

Ademais, as mulheres estão expostas as determinações das políticas públicas de saúde ${ }^{(11,12)}$. As propostas e programas voltados para essa população enfatizam o respeito à autonomia da muIher. No entanto, ao serem colocadas em prática, nos diversos níveis de atenção, as mulheres passam a ser 0 objeto dessas políticas ${ }^{(11)}$, assim como, os enfermeiros, frequentemente, estão submissos às suas normas e diretrizes. A cobrança da chefia pelo cumprimento de metas assistências, muitas vezes, faz com que a opinião das mulheres não seja ouvida pelos enfer meiros.

Os enfermeiros, comumente, aderem linearmente aos programas oficiais do M inistério da Saúde. No entanto, presencia-se a pouca participação desses trabalhadores da saúde na definição e estabelecimento das políticas públicas de saúde. Além disso, muitos programas de saúde instituídos no âmbito nacional não estão se realizando, de acordo com o previsto pelo M inistério da Saúde, vendose frustrados, por resistência dos próprios sujeitos envolvidos, trabalhadores da saúde e população, tendo em vista a descontextual ização social e cultural que representam ${ }^{(13)}$.

Esse fato está, também, atrelado à falta de autonomia do enfermeiro na organização do trabaIho. Consequentemente, nos casos em que o enfermeiro não participa ativamente das decisões que envolvem o contexto do cuidado, em especial, o cuidado de Enfermagem, pode haver a diminuição da participação e o envolvimento das mulheres no processo decisório ${ }^{(14,16)}$.

A autonomia é um importante instrumento de reflexão e ação dos profissionais de saúde sobre sua prática. A ssim, os aspectos que condicionam a liberdade de escolha do paciente, de igual forma precisam estar incorporados pelos profissionais que pretendem favorecer e ampliar esse direito ${ }^{(13,18)}$. 0 cuidado ao outro, implica o cuidado de si, ou seja, ocupar-se de si, para depois, ocupar-se do outro ${ }^{(13)}$.

\section{CONCLUSÕES}

Considera-se que o objetivo proposto nesta revisão foi alcançado, pois foi identificado, em publicações científicas nacionais, como o cuidado de E nfermagem contribui para a participação da muIher no processo decisório no ciclo gravídicopuerperal. A s contribuições que despontaram não o foram apenas em uma per spectiva positiva, mas, também, revelaram limitações que o cuidado de Enfermagem poderá implicar na garantia desse direito da mulher.

A ssim, dentre os resultados encontrados destaca-se a relação existente entre a possibilidade de participação e envolvimento das mulheres nas decisões acerca do cicl o gravídico-puer peral e a autonomia do enfermeiro no contexto do cuidado. A capacidade do enfermeiro de ser autônomo está diretamente ligada ao alcance da cidadania da mulher.

A metodologia da revisão integrativa mostrou-se adequada ao propósito do estudo, favorecendo para a identificação de uma lacuna na área do conhecimento e atuação da Enfermagem, evidenciada pela inexistência de pesquisas da Enfermagem que abordem, especificamente, a participação da mulher no processo decisório no ciclo gravídico-puerperal, e as possíveis contribuições do cuidado de Enfermagem para a garantia desse direito. Há necessidade de estudos voltados para identificar como o cuidado de E nfermagem no ciclo gravídico-puerperal contribui para a participação da mulher no processo decisório, na tentativa de construir estratégias para assegurar esse dir eito das mulheres na atenção à mulher.

Assim, entende-se que o presente estudo traz contribuições significativas para a produção do conhecimento, tanto na pesquisa da Enfermagem, quanto no ensino e for mação do enfer meiro, a perspectiva da mulher como sujeito do processo de cuidado, do seu corpo e do processo reprodutivo, favorece a consolidação de um novo paradigma do cuidado de E nfermagem à saúde da mulher no ciclo gravídico-puerperal.

\section{REFERÊ NCIAS}

1 M inistério da Saúde (BR). Política nacional de atenção integral à saúde da mulher: princípios e diretrizes. Brasília (D F); 2004.

2 Dias M AB, D eslandes SF. Expectativas sobre a assistência ao parto de mulheres usuárias de uma mater nidade pública do Rio de Janeiro, Brasil: os desa- 
fios de uma política pública de humanização da assistência. Cad Saúde Pública. 2006;22(12):2647-55.

3 Griboski RA, Guilbem D. Mulheres e profissionais de saúde: imaginário cultural na humanização ao parto enascimento. T exto Contexto E nferm. 2006;15(1): 107-14.

4 Parada CM G L, T onete VL P. 0 cuidado em saúde no ciclo gravídico puerperal sob a perspectiva de usuárias de serviços públicos. Interface Comun Saúde Educ. 2008;12(24):35-46.

5 W ittmann-Price RA. Emancipation in decisionmaking in women's health care. J Adv Nurs. 2003; 47(4):437-45.

6 W hittemore $R, K$ nafl $K$. T he integrative review: updated methodology. J Adv N urs 2005;52(5):546-53.

7 M enezes KDS, Silveira RCCP, G alvão CM . Revisão integrativa: método de pesquisa para a incor por ação de evidências na saúde e na enfermagem. T exto Contexto Enferm. 2008;17(4):758-64.

8 Severino AJ. M etodologia do trabal ho científico. São Paulo: Cortez; 2002.

9 Queiroz M VO, Silva AO, Jorge M SB. Cuidado de enfermagem à puérpera em uma unidade de internação obstétrica: perspectivas de humanização. Rev Baiana Enferm. 2003;18(1/ 2): 29-37.

10 Progianti JM , Costa RFA. A negociação do cuidado de enfermagem obstétrica através das práticas educativas na casa de parto. Esc Anna Nery Rev Enferm. 2008;12(4);789-92.

11 Souza KV, Cubas M R, A rruda DF, Carvalho PRQ, Carvalho CM G. A consulta puerperal: demandas de mulheres na perspectiva das necessidades sociais em saúde. Rev G aúcha Enferm. 2008;29(2): 175-81.

12 Carraro TEC, Knobel R, Radunz V, M eincke SM, Fiewskt M FC, Frello AT, et al. Cuidado e conforto durante o trabalho de parto e parto: na busca pela opinião das mulheres. Texto Contexto Enferm. 2006;15(n esp):97-104.

13 L unardi VL. Do poder pastoral ao cuidado de si: a governabilidade na enfermagem [ tese]. Florianópolis: U niversidade Federal de Santa Catarina; 1997.

14 Q uitete JB, Vargens OM C. 0 poder no cuidado da enfer meira obstétrica: empoderamento ou submissão das mulheres usuárias? Rev Enferm U E RJ. 2009; 17(3):315-20.

15 I serhard ARM , N eves ET, Budó M LD, Badke M R. Práticas culturais de cuidados de mulheres mães de recém-nascidos de risco do sul do Brasil. Esc Anna Nery Rev Enferm. 2009;13(1):116-22.

16 Castro J C, Clapis M J. Parto humanizado na percepção das enfer meir as obstétricas envolvidas com a assistência ao parto. Rev Latino-Am Enfermagem. 2005;13(6):360-7.

17 Figueirêdo N M A, T yrrell M AR, Carvalho V, Leite JL. Indicadores de cuidado para o corpo que procria: ações de enfermagem no pré, trans e pós-parto: uma contribuição para a prática de enfer magem obstétrica. Rev L atino-A m E nfermagem. 2004;12(6):905-12.

18 F reitas L opes CHA, Chagas NR, Jorge M SB. 0 princípio bioético da autonomia na per spectiva dos profissionais de saúde. Rev G aúcha Enferm. 2007;28 (2):266-73.

\author{
Endereço da autora / Dirección del autor / \\ Author's address: \\ Josefine Busanello \\ Rua D r. M aia, 1921, Centro \\ 97510-160, U ruguaiana, RS \\ E-mail:josefinebusanello@unipampa.edu.br
}

Recebido em: 21/ 11/ 2010

A provado em: 03/ 05/ 2011 